\title{
Uveal malignant melanoma and optic nerve glioma in von Recklinghausen's neurofibromatosis
}

\author{
C Mark Antle, Karim F Damji, Valerie A White, Jack Rootman
}

\begin{abstract}
A case of uveal malignant melanoma and contralateral optic nerve glioma is described in a 53-year-old Caucasian male with multiple uveal melanocytic hamartomas and neurofibromatosis. The eye was enucleated, and histologically the melanoma was found to consist of $70 \%$ epithelioid cells, with many bizarre, multinucleated forms. CT scan demonstrated a non-enhancing, fusiform enlargement of the contralateral optic nerve with enlargement of the optic canal and intracranial extension. This combination of tumours has not previously been reported in a patient with neurofibromatosis and serves to emphasise the common neuroectodermal origin of tumours in this autosomal dominant condition.
\end{abstract}

Optic nerve glioma ${ }^{2}$ and uveal malignant melanoma ${ }^{3-13}$ have both been reported in von Recklinghausen's neurofibromatosis (NF). While the incidence of optic nerve glioma varies from 10 to $70 \%$, ${ }^{2}$ only 11 cases of uveal malignant melanoma in NF are reported. ${ }^{3-13}$ In NF uveal malignant melanoma has been reported with acoustic schwannoma ${ }^{3}$ and with orbital neuroma. ${ }^{5}$ We describe the previously unreported association of uveal malignant melanoma and contralateral optic nerve glioma in a patient with multiple uveal melanocytic hamartomas and neurofibromatosis.

\section{Case report}

A 53-year-old Caucasian man with multiple cutaneous neurofibromata, café-au-lait spots, and a family history of NF presented with a fourday history of spots and blurring in the left eye rapidly progressing to total grey-out of vision.

The visual acuities were $20 / 20-3$ in the right eye and $20 / 400$ in the left, with a left afferent pupillary defect. The interpalpebral fissures, results of exophthalmometry, and IOP measurements were normal and symmetrical. Neither globe showed displacement. Multiple Lisch nodules and iris naevi were seen, particularly in the left eye, which also had a large inferior sentinal vessel and a cataract. There was a large ciliochoroidal tumour between 4 and 8 o'clock, with 9-10 mm of elevation, a total retinal detachment, and anterior iris displacement between 4 and 6 o'clock.

Ultrasonography showed a solid, horseshoe shaped mass in the choroid extending from inferotemporal to inferonasal quadrants.

Computed tomography showed a normal left orbit and a left globe of normal size with an enhancing lobulated uveal mass in its inferior half extending bilaterally to the ora (Fig 1)

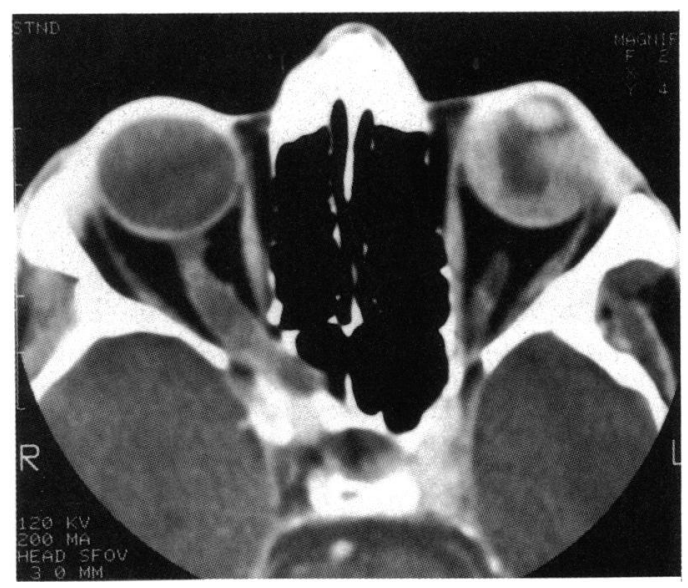

Figure 1 Axial CT scan showing fusiform enlargement of the optic nerve with intracranial extension (right) and lobulated uveal mass (left).

without extrascleral extension. On the right the optic nerve had a non enhancing, fusiform enlargement, with expansion of the optic canal and intracranial extension. No cerebellopontine angle or internal auditory canal abnormality was seen.

Malignant melanoma was suspected, and it was confirmed on intraoperative fine needle aspiration biopsy, which showed numerous malignant epithelioid melanocytes with large vesicular nuclei and prominent nucleoli. The biopsy was followed by a cryoenucleation. The globe was $24-25 \mathrm{~mm}$ in diameter with corneal measurements of $13 \times 11.5 \mathrm{~mm}$. Oblique sectioning exposed a black tumour with a $17 \mathrm{~mm}$ base and a height of $7 \mathrm{~mm}$. The overlying retina was detached.

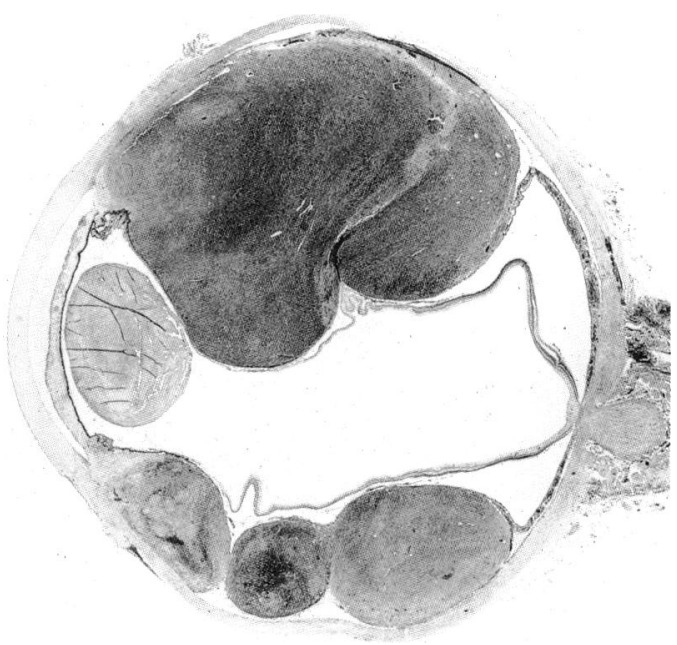

Figure 2 Low power view of globe showing lobulated tumour arising from the uveal tract and associated retinal detachment. (Haematoxylin and eosin, $\times 2 \cdot 7$.) 


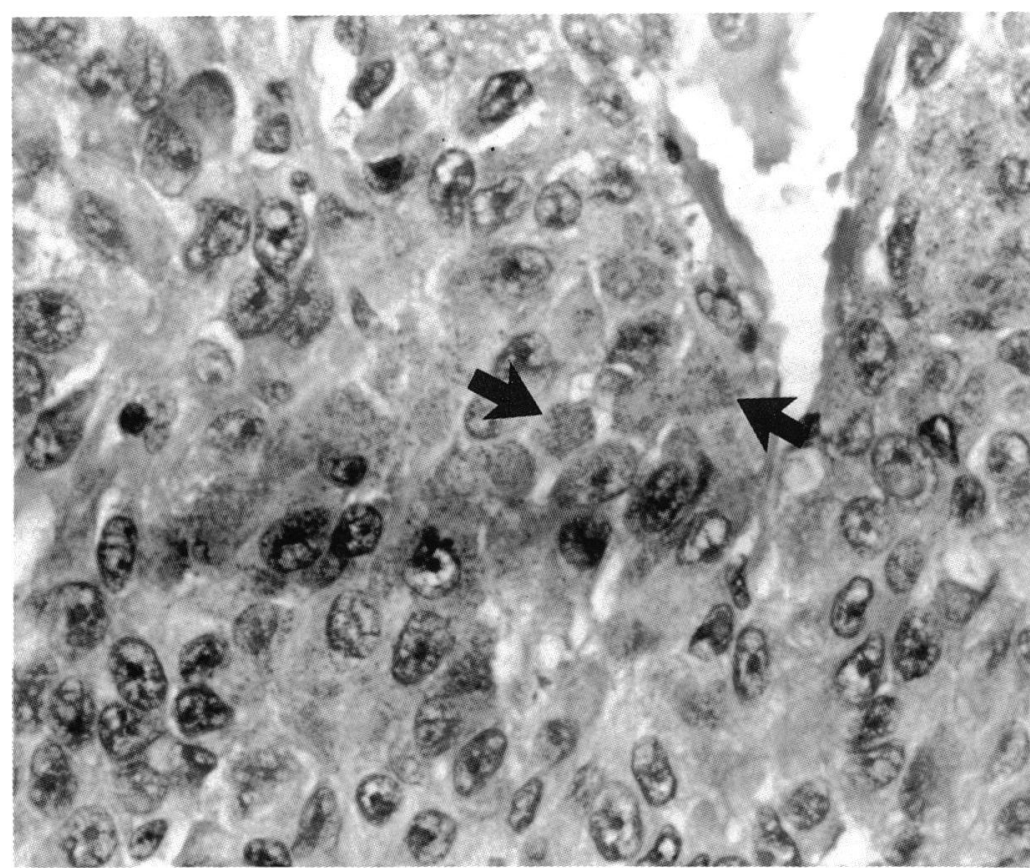

Figure 3 Uveal malignant melanoma with epithelioid cells showing granular cytoplasmic S100 positivity (arrows). (Bleached preparation;

immunoperoxidase staining for S100 antigen; $\times 800$.)
Histologically a poorly differentiated malignant melanoma arose from the uvea, abutted the lens, occupied the pars plana, and extended three-quarters of the way to the posterior pole (Fig 2). The densely pigmented tumour cells were $70 \%$ epithelioid and $30 \%$ spindle, with many bizarre, multinucleated forms (Fig 3). The tumour stained moderately for $\mathrm{S} 100$ protein and strongly with the monoclonal antibody HMB45. Large sinusoidal spaces and focal areas of haemorrhage and necrosis were identified. There was no paraemissarial extension. The detached retina was degenerated.

In the neovascularised iris spindle to polygonal shaped cells, many with intranuclear inclusions, formed numerous S100-positive melanocytic hamartomas (Fig 4). In the choroid multiple diffuse hamartomatous aggregations of melanocytes, some extending round the emissaria posteriorly, were present and stained strongly positive for $\mathrm{S} 100$ protein and occasionally with HMB45 (Fig 5).

The patient presented three months later with diffuse metastatic disease and died 13 months after enucleation.

\section{Discussion}

Neurofibromatosis, first described by von Recklinghausen in $1882,{ }^{14}$ is a common autosomal dominant disorder with a prevalence of 1 in $3000 .{ }^{15}{ }^{16}$ It has one of the highest mutation rates in humans. ${ }^{17}$ Though it was previously considered to be a heterogeneous disorder with variable expression, linkage analysis in NF families has recently identified a consistent mutation at a single locus on chromosome17. ${ }^{18}$

Melanocytic and glial lesions of NF are derived from the neural crest. The association of optic nerve glioma and NF is established, ${ }^{12}$ and an increased incidence of uveal malignant melanoma is also noted ${ }^{19}$ despite the small number of cases (11) reported. ${ }^{3-13}$ Uveal naevi are also found more frequently. ${ }^{11}$ is Concurrent malignant melanoma and optic nerve glioma

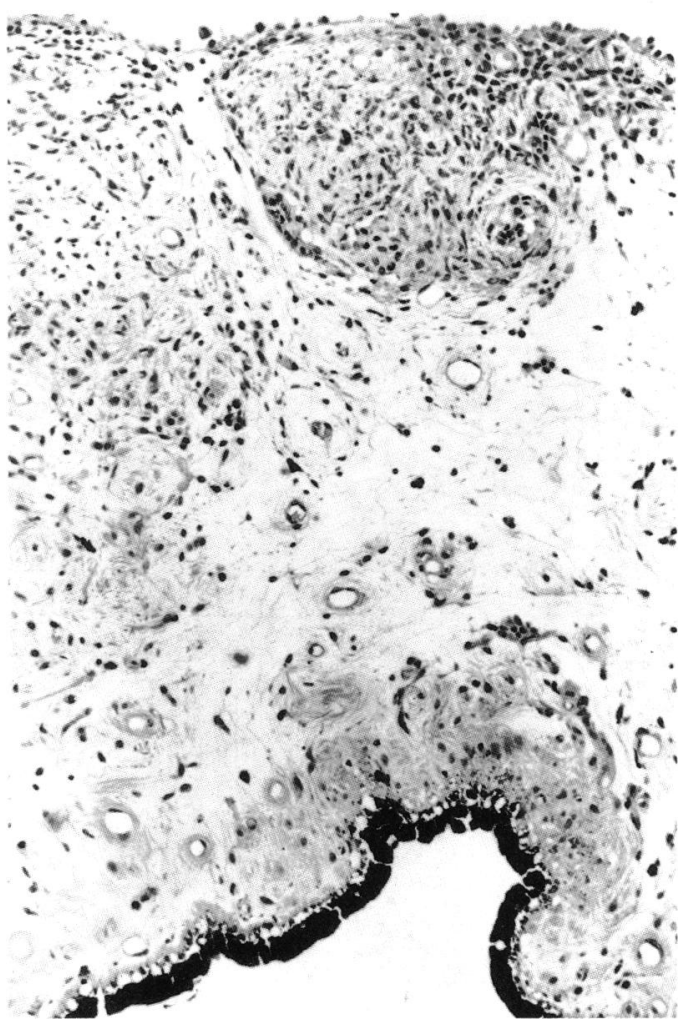

Figure 4 Melanocytic hamartoma of the iris. (Haemotoxylin and eosin, $\times 80$.)

have not previously been reported, but the conjunction illustrates the pathogenesis of NF as a 'complex neurocristopathy' as initially defined by Bolande. ${ }^{20}$ This concept envisages NF as a defect in development and regulation in which tissues derived from the neural crest show an increased incidence of benign tumours such as neurofibromas, schwannomas, neuromas, gliomas, meningiomas, café-au-lait spots, other cutaneous naevi, uveal naevi, ${ }^{121621-23}$ and malignant tumours such as malignant schwannoma, ${ }^{2425}$ pheochromocytoma, ${ }^{26}{ }^{27}$ cutaneous malignant melanoma, ${ }^{2428-30}$ and uveal malignant melanoma..$^{3-13}$ A predisposition to uveal malignant melanoma may also exist because of the increased incidence of choroidal naevi in $\mathrm{NF}^{31}$ and the supposition that malignant melanoma arises from these naevi. ${ }^{32}$

Other features of NF cannot be attributed directly to maldeveloped neural crest but may arise secondarily to interactions with other developing tissues, leading to additional anomalies ${ }^{15}$ such as malignant tumours (rhabdomyosarcoma, nephroblastoma, and myelogenous leukaemia), ${ }^{33-37}$ mesodermal defects (macrocephaly, pseudoarthrosis, kyphoscoliosis, short stature, sphenoid wing dysplasia), diminished intellect, speech defects, and pruritus. ${ }^{16}$

The commonest ocular feature of NF is the Lisch nodule, present in over $90 \%$ of adult patients. ${ }^{22}$ Additional neural crest derived ocular features include neurofibromas of eyelid, conjunctiva, and orbit, café-au-lait spots, prominent corneal nerves, uveal naevi, choroidal glial hamartomas, optic nerve gliomas, intraocular schwannomas, sphenoid wing dysplasia, ${ }^{1722} 2338$ and uveal malignant melanoma. ${ }^{3-13}$

The average age of patients with NF-related 


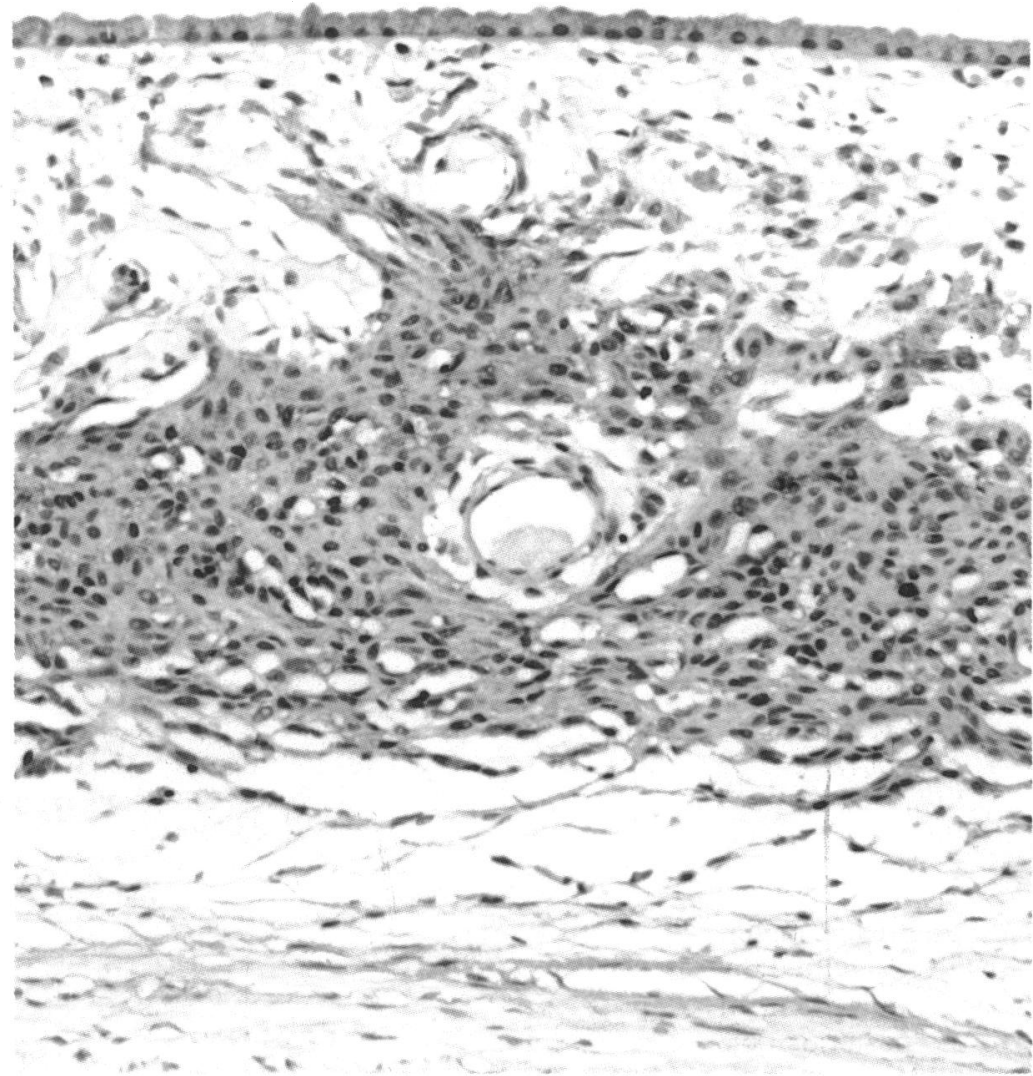

Figure 5 Melanocytic hamartoma of the choroid. (Immunoperoxidase staining for $S 100$ antigen, $\times 160$.)
8 Nordmann J, Brini A, Ruolt J. Temeur melanique de la choroide et neurinomes chez un même sujet. Bull Soc Ophtalmol Fr 1963; 7: 551-3.

9 Yanoff M, Zimmerman LE. Histogenesis of malignant melanomas of the uvea: III. The relationship of congenita ocular melanocytosis and neurofibromatosis to uvea melanomas. Arch Ophthalmol 1967; 77: 331-6.

10 Cernea P, Dobrescu G. Mélanome malin uvéal, manifestation de la maladie de Recklinghausen. Ophthalmologica 1973, 166: $161-71$.

11 Wiznia RA, Freedman JK, Mancini AD, Shields JA. Malignant melanoma of the choroid in neurofibromatosis. $A m \mathcal{F}$ Ophthalmol 1978; 86: 864-87.

12 Croxatto JO, Charles DE, Malbran ES. Neurofibromatosis associated with nevus of Ota and choroidal melanoma. Am associated with nevus of Ota and

13 Specht CS, Smith TW. Uveal malignant melanoma and von Recklinghausen's neurofibromatosis. Cancer 1988; 62: Recklin

14 Crump $T$. Translation of case reports in Ueber die multiplen Fibrome der Haut und ihre Beziehung zu den multiplen Neuromen bei F.v. Recklinghausen. Adv Neurol 1981; 29 259-76.

15. To KW, Rabinowitz SM, Friedman AH, Merker C, Cavanaugh CP. Neurofibromatosis and neural crest neoplasms: primary acquired melanosis and malignant melanoma of the choroid. Surv Ophthalmol 1989; 33: 373-9.

16 Riccardi VM. von Recklinghausen neurofibromatosis. N Engl F Med 1981; 305: 1617-27.

17 Sergeyev AS. On the mutation rate of neurofibromatosis. Hum Genet 1975; 28: 129-38.

18 Barker D, Wright E, Nguyen $\mathrm{K}$, et al. Gene for von Recklinghausen neurofibromatosis is in the pericentromeric region of chromosome 17 . Science 1987; 236: 1100-2.

19 Font RL, Ferry AP. The phakomatoses. Int Ophthalmol Clin $1972 ; 12: 31-42$.

20 Bolande RP. The neurocristopathies: a unifying concept of disease arising in neural crest maldevelopment. Hum Pathol 1974; 5: 409-29.

21 Huson S, Jones D, Beck L. Ophthalmic manifestations of neurofibromatosis. Br 7 Ophthalmol 1987; 71: 235-8.

22 Lewis RA, Riccardi VM. von Recklinghausen neurofibromatosis. Incidence of iris hamartoma. Ophthalmology 1981; 88: $348-54$.

23 Ilgren EB, Kinnier-Wilson IM, Stiller CA Gliomas in neurofibromatosis: a series of 89 cases with evidence for enhanced malignancy in associated cerebellar astrocytomas. Pathol Annu 1985; 1: 331-58.

24 Brasfield RD, Das Gupta TK. von Recklinghausen's disease: clinico-pathologic study. Ann Surg 1972;175: 86-104.

25 Sayed AK, Bernhardt B, Perez-Atayde AR, et al. Malignan schwannoma in siblings with neurofibromatosis. Cancer 1987; 59: 829-35.

and our patient was 55 tions for uveal malignant melanoma in the general population occur after age $50 .^{39}$ Despite the lack of sex predilection in NF alone, nine of the 11 previously reported patients in whom it was associated with uveal malignant melanoma were female, a distribution not seen in other series of uveal malignant melanoma. Seven tumours were reported as spindle cell, three as mixed cell, and one as epithelioid cell. The tumour in our case was mixed. Four cases showed extrascleral extension at enucleation, while the present case did not. The malignant cell type of our tumour and the large size suggested a poor outcome, with a five-year survival less than $40 \%$. $^{40}$

1 Rush JA, Younge BR, Campbell RJ, MacCarthy CS. Optic glioma. Long term follow-up of 85 histopathologically verified cases. Ophthalmology 1982; 89: 1213-9.

2 Lewis RA, Gerson LP, Axelson KA, Riccardi VM, Whitford RP. von Recklinghousen neurofibromatosis. II. Incidence of optic gliomata. Ophthalmology 1984; 91: 929-35.

3 Bair HL, Love JG. Acoustic neurofibroma associated with melanoepithelioma of the choroid: successful removal of both tumors. Mayo Clin Proc 1937; 12: 481-5.

4 Gartner S. Malignant melanoma of the choroid and von Recklinghausen's disease. Am 7 Ophthalmol 1940; 23: 73-8.

5 Strachov VP. Recklinghausen's disease, neurinoma of the right orbit and neoplasm of the left choroid. Vestn Oftalmol 1941; 18: 12-16 (in Russian).

6 Szekler R. Ein Uvealsarkom bei einem Mitglied einer Familie mit Recklinghausenscher Krankheit. Ophthalmologica 1954 126: 248-51

7 Nordmann J. Cancer de la choroide et maladie de Recklinghausen. Bull Soc Ophtalmol Fr 1961; 5: 322-5.
26 Healy FH, Mekelatos CJ. Pheochromocytoma and neurofibromatosis. N Engl f Med 1958; 258: 540-3.

27 Modlin IM, Farndon JR, Shephard A, et al. Pheochromocytoma in 72 patients: clinical and diagnostic feature cytoma in 72 patients: clinical and diagnostic feature,

28 Riccardi VM, Eichner JE. Neurofibromatosis: phenotype, natural sity Press, 1986: 162-8.

29 Silverman JF, Blahove M, Collins JL, Norris HT. Cutaneou malignant melanoma in a black patient with neurofibromatosis. Am 7 Dermatopathol 1988; 10: 536-40.

30 Mastrangelo MJ, Goepp CE, Patel YA, Clark WH. Cutaneous melanoma in a patient with neurofibromatosis. Arch Dermatol 1979; 115: 864-5.

31 Hope DG, Mulvihill JJ. Malignancy in neurofibromatosis. Adv Neurol 1981; 29: 33-56.

32 Yanoff $M$, Zimmerman, LE Histogenesis of malignant melanoma of the uvea. Arch Ophthalmol 1967; 77: 331-6.

33 Bader JL, Miller RW. Neurofibromatosis and childhood leukemia. F Pediatr 1978; 92: 925-9.

34 Bestak M, Miller DR, Mouradian JS. Juvenile chronic myelo1979; 133: 831-3

35 McKeen EA, Bodurtha J, Meadows AT, et al. Rhabdomyosarcoma complicating multiple neurofibromatosis. 7 Pedia 1978; 93: 992-3.

36 Stay EJ, Vawter G. The relationship between nephroblastoma and neurofibromatosis. Cancer 1977; 39: 2550-5.

37 Walden PAM, Johnson AG, Bagshawe KD. Wilms's tumour and neurofibromatosis. BrMed 7 1977; i: 813.

38 Freedman SF, Elner VM, Donev ID, Gunta G. Albert DM. Intraocular neurilemmoma arising from the posterior ciliary nerve in neurofibromatosis. Ophthalmology 1988; 95

39 Zimmerman LE. Malignant melanoma of the uvea. In Spencer WH, ed. Ophthalmic pathology. Philadelphia:

40 McLean IW, Foster WD, Zimmerman LE. Uveal melanoma location, size, cell type and enucleation as risk factors in metastasis. Hum Pathol 1982; 13: 123-32. history and pathogenesis. Baltimore: Johns Hopkins Univergenous leukemia and dermal histiocytosis. Am $\mathcal{F}$ Dis Child Saunders, 1986: 2072-136. 